\title{
Disease prevalence in a rural Andean population of central Peru: a focus on autoimmune and allergic diseases
}

\author{
Giorgio Caturegli ${ }^{1}$ Patrizio Caturegli ${ }^{2,3}$
}

Received: 8 November 2015/Accepted: 19 January 2016/Published online: 10 February 2016

(C) The Author(s) 2016

\begin{abstract}
Introduction The hygiene hypothesis, formulated to explain the increased incidence of allergic and autoimmune diseases observed in industrialized countries, remains controversial. We reflected upon this hypothesis during a medical mission to rural and impoverished villages of central Peru.

Materials and methods The mission was carried out in July 2015 to aid three Andean villages located near Cusco, and comprised 10 American physicians, 4 nurses, and 24 students. After recording the vital signs, patients were triaged by nurses based on the major complaint, visited by physicians, and prescribed medications. Physicians wrote their notes on a one-page form and established diagnoses purely on clinical grounds, without laboratory or imaging testing. Physician notes were then analyzed retrospectively in a de-identified and double-blinded fashion.

Results A total of 1075 patients (357 men and 718 women) were visited during 5 consecutive clinic days, 840 being adults and $235<18$ years of age. The most common
\end{abstract}

Electronic supplementary material The online version of this article (doi:10.1007/s13317-016-0076-z) contains supplementary material, which is available to authorized users.

Giorgio Caturegli

g.caturegli96@gmail.com

Yale University, New Haven, CT, USA

2 Department of Pathology, School of Medicine, The Johns Hopkins University, Baltimore, MD, USA

3 Department of Molecular Microbiology and Immunology, Bloomberg School of Public Health, The Johns Hopkins University, Baltimore, MD, USA complaints were back pain, stomach pain, headache, and vision loss. Osteoarthritis, gastritis, visual disturbances, and parasitic infections dominated the diagnostic categories. Thirty-seven patients ( $3 \%$ ) were diagnosed with an allergic or autoimmune disease, mainly represented by asthma, rheumatoid arthritis, and Hashimoto's thyroiditis, a prevalence that was not significantly lower than that reported in industrialized countries.

Conclusions Although a study of this nature cannot definitively support or refute the hygiene hypothesis, it does provide a novel snapshot of disease prevalence in rural Andean villages of central Peru. The study could serve as a basis to implement basic public health interventions and prepare for future missions to the same or comparable regions.

Keywords Hygiene hypothesis - Autoimmunity · Epidemiology

\section{Introduction}

The "hygiene hypothesis" was proposed by Strachan [1] to explain the increased prevalence of allergic diseases in countries that enjoy "improved household amenities and higher standards of personal cleanliness". A few years later, the same hypothesis was used to explain the increased prevalence of autoimmune diseases reported in Western countries [2]. In essence, this hypothesis envisions a direct relationship between the cleanliness of the environment in which humans live and the incidence of allergic and autoimmune conditions: the cleaner and more devoid of infectious agents the environment is, the greater the incidence of allergy and autoimmunity. Recently, Clarke et al. [3] reported that living in rural, thus less "clean", 
areas during early childhood significantly reduced the risk of developing papillary thyroid cancer in adulthood. Over the past two decades, several studies have evaluated the association between environmental infections (mainly parasitic) and autoimmune diseases such as multiple sclerosis and [4, 5] inflammatory bowel disease [6], suggesting that exposure to microbes imprints and calibrates the immune system so as to not overreact against the host. In keeping with these findings, Shoenfeld et al. have demonstrated that the experimental administration of helminth products, such as phosphorylcholine combined with tuftsin, ameliorated morbidity and mortality in a murine model of systemic lupus erythematosus [7], highlighting new interventional approaches based on infectious agents for the treatment of autoimmune and allergic diseases [8]. While the mechanism underlying the hygiene hypothesis remains to be defined, recent evidence suggests that parasite-driven protection is associated with induction of regulatory T cells [9] as well as regulatory B cells [10].

Peruvian Quechua can overall be considered a population not enjoying household amenities and not having higher standards of personal cleanliness. They are indigenous Amerindians, descendant of the Incas, who currently make up to $45 \%$ of the Peruvian population. They are typically rural and impoverished [11], and often rely on folk medicine for the treatment of various diseases [12]. Centuries of exposure to high altitude (i.e., higher than $2500 \mathrm{~m}$ above sea level) have induced genetic polymorphisms and physiological responses that allow Quechua to survive chronic hypoxia and cold temperatures. Several studies have revealed these genetics and environmental adaptions (summarized in Supplemental Table 1) by comparing Quechua born and raised at high altitude to those born and raised at sea level. On the contrary, only limited information is available regarding autoimmune diseases in Andean populations. Toloza et al. [13] analyzed the prevalence of psoriasis and psoriatic arthritis in 8191 consecutive patients seen at the arthritis clinic in the Juliaca Hospital of Puno over a period of 3 years (2008-2011). The authors identified 16 cases, yielding a period prevalence $(0.2 \%)$ that is not significantly different from the lifetime prevalence of psoriasis observed in Denmark in 2001 [14].

Recently, we participated in a medical mission to Andean villages of central Peru organized by the non-profit charity Hands Across the Americas. We took this opportunity to analyze the overall disease prevalence in patients attending the mission clinics, reflect upon the hygiene hypothesis, and provide a benchmark for guiding future missions in similar areas.

\section{Materials and methods}

\section{Settings}

The medical mission was carried out in the three rural villages of Huarocondo (day 1), Ancahuasi (days 2-3), and Anta (days 4-5) over the course of 5 days in July 2015. These villages, located at approximately $50 \mathrm{~km}$ from Cusco, are situated at about $3300 \mathrm{~m}$ above the sea level and comprise a population of approximately 30,000 Amerindian people. Patients came spontaneously to the clinic and were seen on a first-come, first-served basis until the day was over. The mission was conducted by 10 American physicians and 4 nurses, with the assistance of 24 students. After registration, patients were seen by a nurse to record vital signs [blood pressure, heart rate, respiration rate, temperature (mainly in children), and body weight], and then triaged to the various physicians (5 internists, 2 gynecologists, 1 pediatrician, 1 otorhinolaryngologist, and 1 psychiatrist) according to the major complaint. Physicians hand-wrote notes and prescriptions on a printed onepage form and established diagnoses purely on clinical grounds, without the aid of laboratory or imaging studies. These diagnoses reflected the clinical expertise of the participating physicians, none of whom had received specialized training in autoimmune and allergic diseases. Following the visit, patients were escorted to a tent pharmacy where they received instructions and medications. Medications, donated by various institutions or purchased through private donations, had been shipped from the United States prior to the mission.

\section{Study design}

This cross-sectional study analyzed after completion of the mission the clinical notes physicians had taken. Physicians were unaware of the study and thus provided an unbiased assessment of the disease prevalence in this region. Deidentified patient notes were manually entered into a FileMaker database (FileMaker Inc., Santa Clara, CA), and then analyzed with Stata (software release 14, from Stata Corporation, College Station, TX). The study was considered exempt from institutional review board evaluation on the basis of federal regulation 45 CFR 46.101(b) (research involving the study of existing data recorded in such a manner that subjects cannot be identified). Differences in means between two groups were assessed by Student's $t$ test, and differences in proportions by Fisher's exact test. Simple linear regression was used to analyze the association of blood pressure with age, and heart rate with age. 


\section{Results}

\section{Demographics}

A total of 1075 patients were examined by ten physicians in 5 days. Of the patients, 235 were children $(<18$ year old, 123 boys and 112 girls) and 840 adults (234 men and 606 women). The majority of patients (961 of 1075, $89 \%$ ) were seen by only one physician; the remaining minority $(114,11 \%)$ had more than one visit, for a total of 1196 visits (Supplemental Table 2). Age ranged from 6 months to 107 years (Fig. 1a). In children, age had a median of 4, a mean of 6 , and a standard deviation of 5 years, and did not differ between males and females (Fig. 1b). In adults, age had a median 56 years, a mean of 55 , a standard deviation
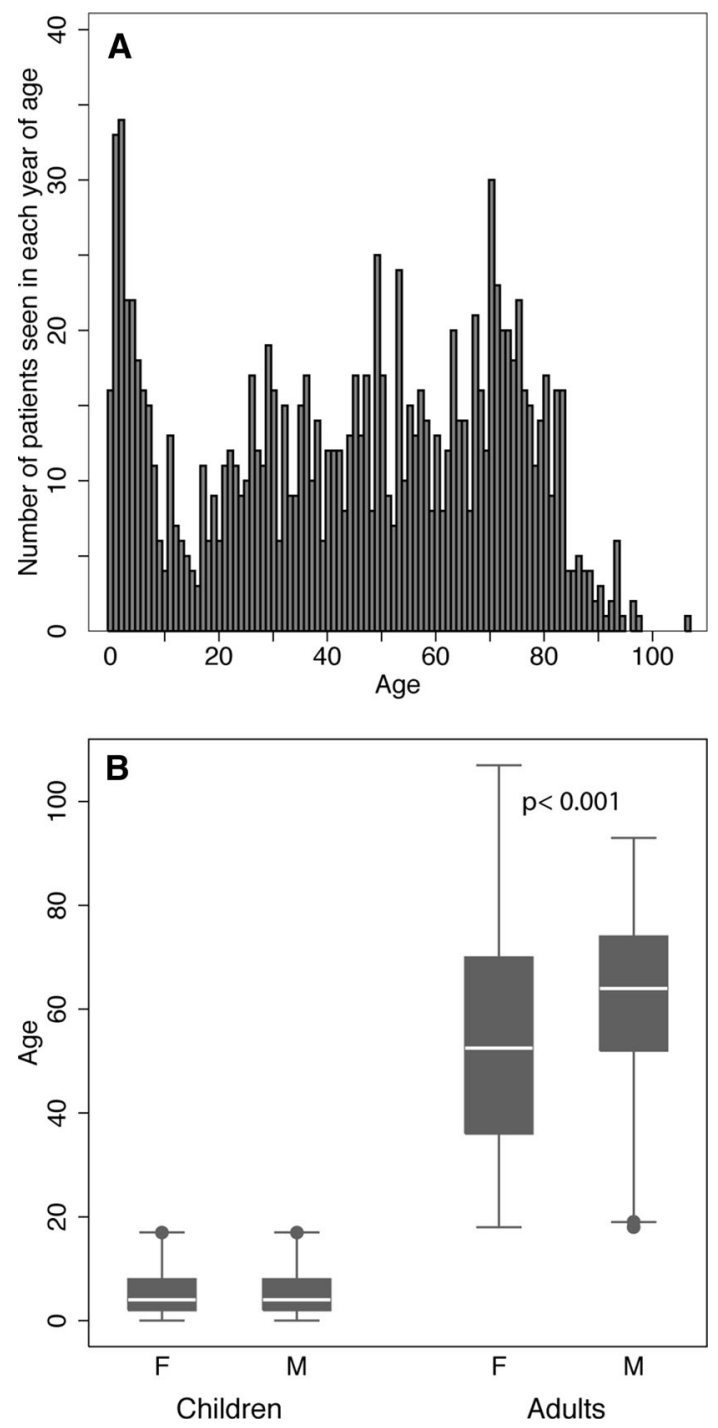

Fig. 1 a Age distribution of the 1075 patients seen according to their age. b Distribution of the patient ages according to gender (male or female) and group (children or adults) of 19 , and was significantly greater in males $(61 \pm 18)$ than females (53 $\pm 20, p<0.0001$, Fig. 1b).

\section{Vital signs}

Blood pressure was measured in most adults ( 808 of 840 , $96 \%, 582$ women and 226 males), and in a few children (17 of $235,7 \%$ ). The overall prevalence of hypertension (defined as a systolic pressure $>140 \mathrm{mmHg}$ and/or a diastolic pressure $>90 \mathrm{mmHg}$ ) in men was $27 \%$ (60 of 226), a value similar to the one (30\%) reported in the 2011-2012 National Health and Nutrition Examination Survey [15]. In women, the prevalence of hypertension was significantly lower than in men (76 of 582, $13 \%$, $p<0.001)$, and lower than that $(28 \%)$ reported in the United States [15]. The mean arterial blood pressure was significantly associated with age, increasing about $2.5 \mathrm{mmHg}$ (95\% confidence interval from 2 to 2.9 , $p<0.001$ ) for every decade increase in age (Fig. 2a).

Resting heart rate was measured in most adults (738 of $840,88 \%$ ) and a few children ( 20 of $235,9 \%$ ). It was normal (i.e., comprised between 60 and 100 beats per minute) in the majority of patients. One patient, seemingly asymptomatic, was found to have a heart rate of 162 and shortness of breath; treatment with metoprolol was started and arrangements were made to transfer him to an emergency department. Five additional patients had heart rates between 105 and 115, but were asymptomatic and left untreated. A significant proportion of patients (78 of 1075, $7 \%$ ) had a heart rate below 60. They were also asymptomatic and left untreated. Heart rate did not significantly change with age (Fig. 2b).

\section{Reasons for the visit}

A total of 2299 complaints were reported by the patients who elected to come to the clinic. The most common complaint was back pain ( 223 of 2299, $10 \%$ ), followed by stomach pain $(208,9 \%)$, headache $(206,9 \%)$, large joint pain $(184,8 \%)$, and vision loss $(169,7 \%$, Table 1$)$.

\section{Diagnoses}

A total of 1661 diagnoses were established by the visiting physicians. The most common diagnosis was osteoarthritis (343 of 1661, $21 \%$ ), followed by gastritis $(149,9 \%$ ), visual disturbances $(124,7 \%)$, and parasitic infections $(119,7 \%$, Table 2). The latter ones were more commonly found in children (104 of $235,44 \%)$ than in adults (15 of 840, $2 \%$, $p<0.001)$. Thirty-seven of the total 1075 patients $(3 \%)$ were diagnosed with diseases considered allergic or autoimmune, the most common of which were asthma, rheumatoid arthritis, and Hashimoto's thyroiditis (Table 3). 

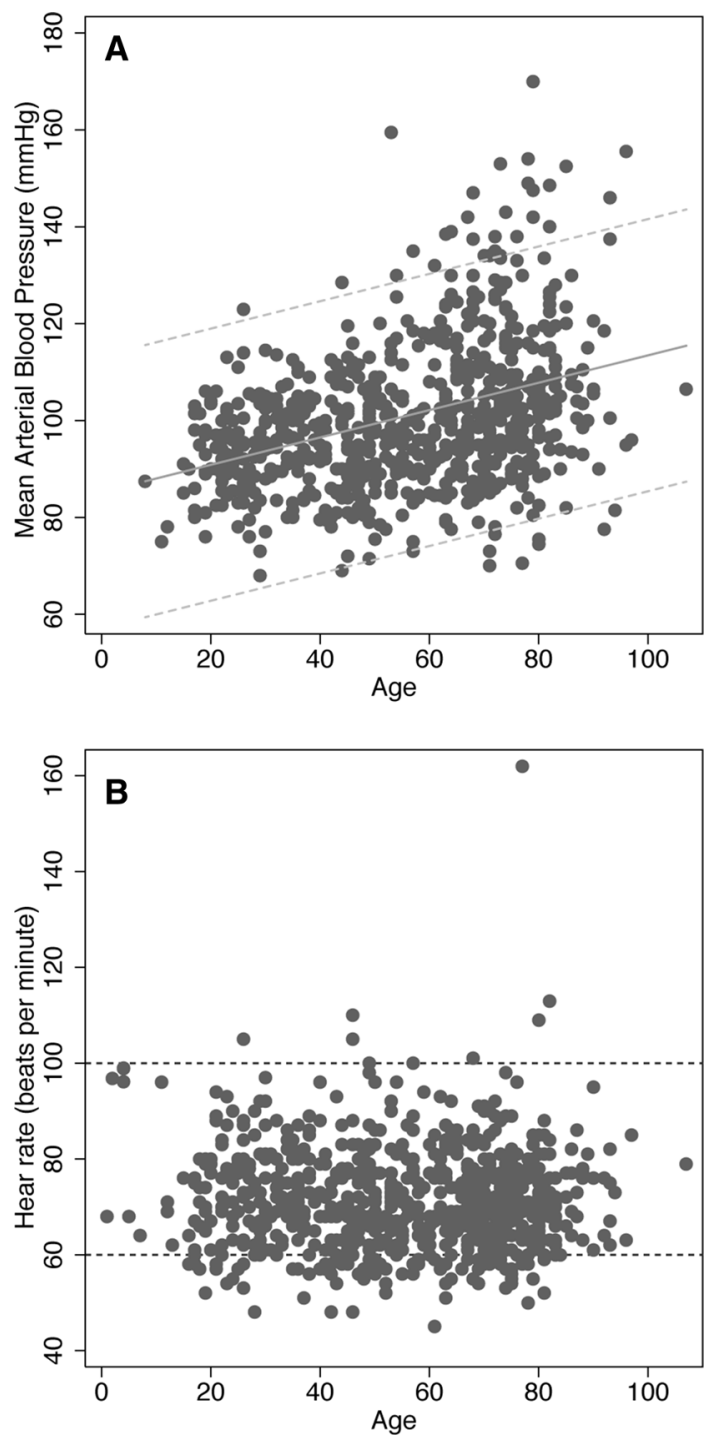

Fig. 2 Blood pressure and heart rate. a Significant association of mean arterial blood pressure with age. Dotted lines represent the $95 \%$ confidence interval around the linear fit. b Lack of association between heart rate and age. Dotted lines represent the upper (100) and lower (60) normal beats per minute

\section{Medications prescribed}

A total of 1648 medications were prescribed by the visiting physicians, mainly represented by acetaminophen (361 of $1648,22 \%)$, ibuprofen $(261,16 \%)$, albendazole $(118$, $7 \%)$, ranitidine $(116,7 \%)$, and metronidazole $(79,5 \%$, Table 4).

\section{Discussion}

This study analyzed the overall prevalence of diseases affecting Amerindian people living in a rural and mountainous region of central Peru. Given its cross-sectional and
Table 1 Reasons for the total 2299 visits, classified according to their origin

\begin{tabular}{|c|c|c|}
\hline & Number & Percentage \\
\hline Head & 655 & 28 \\
\hline Headache & 206 & \\
\hline Vision loss & 169 & \\
\hline Hearing loss & 93 & \\
\hline Tooth pain & 27 & \\
\hline Sore throat & 26 & \\
\hline Lacrimation & 20 & \\
\hline Others & 114 & \\
\hline Joints and muscles & 632 & 27 \\
\hline Back pain & 223 & \\
\hline Large joints pain & 184 & \\
\hline Others & 225 & \\
\hline Gastrointestinal & 336 & 15 \\
\hline Stomach pain & 208 & \\
\hline Diarrhea & 23 & \\
\hline Abdominal pain & 22 & \\
\hline Constipation & 21 & \\
\hline Acid reflux & 21 & \\
\hline Others & 41 & \\
\hline Genitourinary & 218 & 10 \\
\hline Vaginal discharge & 91 & \\
\hline Pelvic pain & 44 & \\
\hline Dysuria & 28 & \\
\hline Vaginal pruritus & 12 & \\
\hline Vaginal bleeding & 6 & \\
\hline Others & 37 & \\
\hline Heart and lungs & 157 & 7 \\
\hline Cough & 61 & \\
\hline Chest pain & 30 & \\
\hline Runny nose & 28 & \\
\hline Difficult breathing & 15 & \\
\hline Others & 23 & \\
\hline Constitutional & 137 & 6 \\
\hline Appetite loss & 69 & \\
\hline Fever & 28 & \\
\hline Weight loss & 23 & \\
\hline Cold intolerance & 5 & \\
\hline Others & 12 & \\
\hline Neuropsychiatric & 82 & 3 \\
\hline Domestic problems & 17 & \\
\hline Sadness & 12 & \\
\hline Difficulty sleeping & 8 & \\
\hline Anxiety & 6 & \\
\hline Loneliness & 4 & \\
\hline Others & 35 & \\
\hline Skin & 43 & 2 \\
\hline Rash & 19 & \\
\hline
\end{tabular}


Table 1 continued

\begin{tabular}{lcc}
\hline & Number & Percentage \\
\hline Itchiness & 8 & \\
Photosensitivity & 3 & \\
Dryness & 2 & \\
Hair loss & 2 & \\
Others & 9 & 2 \\
Trauma & 39 & \\
\hline
\end{tabular}

unbiased nature, the study offers a novel snapshot of this population health, as assessed on purely clinical grounds (i.e., without the aid of imaging or laboratory tests).

The most prevalent diseases were those caused by the environment in which patients lived and worked. Osteoarthritis, the inevitable consequence of years of physical labor in the agricultural fields, involved mainly the back, hands, knees, and shoulders, and often caused significant impairment. Gastritis was likely attributable to the beverages Quechua people drink. Households, often lacking running water, make large use of chicha de jora, a corn-derived beer that dates back to Incan times. It is cheap and considered by the locals more a way of life than a drink, endowed with health benefits for all ages. Although chicha's composition is not fully characterized, its alcoholic content is not negligible (around $2 \%$ ) and can contribute to gastric irritation upon prolonged usage. In addition, the yeasts responsible for chicha's fermentation have a phenotype that markedly differs from that of traditional Saccharomyces cerevisiae strains [16]. Vision impairment was common in both children and adults, an expected consequence of living at high altitude where exposure to ultraviolet radiation is higher [17]. For example, in children living in mountainous regions of Nepal the most common ocular morbidity (38 of 140 subjects, $27 \%$ ) was myopia [18]. In adults, high altitude has been associated with increased prevalence of dry eye syndrome, cataract, corneal thickness, photokeratitis, and retinopathy $[19,20]$.

Parasitic infections were commonly diagnosed in children. The type of parasite was not characterized in this study, but it was most likely Taenia solium tapeworm since it is endemic in much of Peru, with the greatest prevalence in rural communities [21]. In adults, bacterial and viral infections of the upper respiratory tract and bacterial and fungal infections of the female genitourinary tract were the most common. Since the early days of autoimmunity (mid 1950s), infections have been considered a cause, or trigger, of autoimmunity [22, 23]. Indeed there are animal models where autoimmunity is induced by infection, for example the Theieler's virus model of multiple sclerosis in mice
Table 2 Diagnoses $($ No. $=1661)$ established by the physicians, classified according to the organ system

\begin{tabular}{|c|c|}
\hline & Number $(\%)$ \\
\hline Joints and muscles & $400(24 \%)$ \\
\hline Osteoarthritis & 343 \\
\hline Sciatica & 7 \\
\hline Degenerative disc disease & 6 \\
\hline Others & 44 \\
\hline Gastrointestinal & $333(20 \%)$ \\
\hline Gastritis & 149 \\
\hline Parasitic infestation & 118 \\
\hline Gastroesophageal reflux & 32 \\
\hline Biliary stone disease & 11 \\
\hline Gastro-enteritis & 8 \\
\hline Others & 15 \\
\hline Eyes and ENT & $326(20 \%)$ \\
\hline Keratitis (dry eye syndrome) & 69 \\
\hline Cataract & 55 \\
\hline Tooth cavities and abscesses & 52 \\
\hline Earwax blockage & 12 \\
\hline Pharyngitis & 12 \\
\hline Others & 126 \\
\hline Genitourinary & $172(10 \%)$ \\
\hline Vaginitis & 43 \\
\hline Urinary tract infection & 42 \\
\hline Vaginosis & 39 \\
\hline Pelvic inflammatory disease & 17 \\
\hline Benign prostatic hyperplasia & 10 \\
\hline Others & 21 \\
\hline Heart and lungs & $147(9 \%)$ \\
\hline Hypertension & 59 \\
\hline Upper respiratory infection & 23 \\
\hline Rhinitis & 21 \\
\hline Bronchitis & 19 \\
\hline Asthma & 7 \\
\hline Allergic rhinitis & 4 \\
\hline Others & 18 \\
\hline Skin & $107(6 \%)$ \\
\hline Eczematous dermatitis & 48 \\
\hline Pterygium & 12 \\
\hline Dermatitis & 9 \\
\hline Varicose veins & 5 \\
\hline Onychomycosis & 4 \\
\hline Vitiligo & 4 \\
\hline Others & 25 \\
\hline Neuropsychiatric & $83(5 \%)$ \\
\hline Depression & 24 \\
\hline Migraine & 17 \\
\hline Anxiety & 8 \\
\hline Guillain-Barré disease & 4 \\
\hline
\end{tabular}


Table 2 continued

\begin{tabular}{ll}
\hline & Number (\%) \\
\hline Others & 30 \\
Endocrine & $60(4 \%)$ \\
Diabetes type 2 & 16 \\
Malnutrition & 14 \\
Obesity & 14 \\
Hashimoto thyroiditis & 4 \\
Thyroid nodules & 4 \\
Others & 8 \\
Recent trauma or wound & $33(2 \%)$ \\
\hline
\end{tabular}

Table 3 Frequency of allergic and autoimmune diseases diagnosed solely on clinical grounds in 1075 Amerindian Peruvian patients

\begin{tabular}{lcl}
\hline & No. & \% of 1075 \\
\hline Asthma & 7 & 0.7 \\
Rheumatoid arthritis & 5 & 0.5 \\
Hashimoto thyroiditis & 4 & 0.4 \\
Allergic rhinitis & 4 & 0.4 \\
Guillain-Barré syndrome & 4 & 0.4 \\
Vitiligo & 4 & 0.4 \\
Food allergy & 2 & 0.2 \\
Addison's disease & 1 & 0.1 \\
Celiac disease & 1 & 0.1 \\
Fibromyalgia & 1 & 0.1 \\
Giant cell arteritis & 1 & 0.1 \\
Postpartum thyroiditis & 1 & 0.1 \\
Psoriasis & 1 & 0.1 \\
Temporal arteritis & 1 & 0.1 \\
Total & 37 & \\
\hline
\end{tabular}

[24]. In humans, however, proving that infections cause autoimmunity has been challenging. In more recent years (late 1980s), actually, the opposite hypothesis has been formulated. According to the "hygiene hypothesis", infections protect from autoimmunity, so that populations living in less "clean" environments should have a lower prevalence of autoimmunity $[1,2]$. In keeping with the hygiene hypothesis, parasitic infections have been shown to promote beneficial (T-helper 2) immune responses and suppress pro-inflammatory (T-helper 17) ones [25]. The literature, however, remains unclear regarding the complex relationship between infections and autoimmunity. In this study, autoimmune and allergic conditions were diagnosed at a prevalence of $3 \%$, which appears lower than what has been reported in developed countries. For example, recent
Table 4 Distribution of 1648 medications prescribed by ten physicians, according to the pharmaceutical class

\begin{tabular}{|c|c|}
\hline Pharmaceutical Class & Number prescribed (\%) \\
\hline Analgesics & $635(38 \%)$ \\
\hline Acetaminophen & 361 \\
\hline Ibuprofen & 261 \\
\hline Others & 13 \\
\hline Antimicrobials & $431(26 \%)$ \\
\hline Albendazole & 118 \\
\hline Metronidazole & 79 \\
\hline Clindamycin & 47 \\
\hline Amoxicillin & 45 \\
\hline Fluconazole & 45 \\
\hline Others & 97 \\
\hline Gastrointestinal drugs & $220(13 \%)$ \\
\hline Ranitidine & 116 \\
\hline Tums & 49 \\
\hline Omeprazole & 28 \\
\hline Others & 27 \\
\hline Heart and lungs drugs & $145(9 \%)$ \\
\hline Benadryl & 30 \\
\hline Hydrochlorothiazide & 22 \\
\hline Enalapril & 16 \\
\hline Lisinopril & 15 \\
\hline Sudafed & 14 \\
\hline Albuterol & 13 \\
\hline Others & 35 \\
\hline Eyes and ENT drugs & $115(7 \%)$ \\
\hline Dry eye drops & 76 \\
\hline Nasal spray & 12 \\
\hline Earwax removal drops & 11 \\
\hline Erythromycin eye drops & 9 \\
\hline Others & 7 \\
\hline Skin topicals & $74(4 \%)$ \\
\hline Hydrocortisone cream & 45 \\
\hline Antibiotic ointment & 7 \\
\hline Desitin & 4 \\
\hline Others & 18 \\
\hline Neuropsychiatric drugs & $18(1 \%)$ \\
\hline Fluoxetine & 8 \\
\hline Cyclobenzaprine & 5 \\
\hline Others & 5 \\
\hline Prednisone & $10(0.6 \%)$ \\
\hline
\end{tabular}

analyses quote a prevalence of autoimmune diseases around $5 \%[14,26,27]$ and allergic diseases as high as $44 \%$ [28]. Nevertheless, it is important to emphasize that our findings of $3 \%$ prevalence are likely an underestimate of the true prevalence, as diagnoses relied purely on the 
clinical skills of participating physicians, none of whom received specialized training in clinical immunology. This limitation makes it difficult to establish whether rural populations living in central Peru are protected from autoimmunity and allergy through the hygiene hypothesis mechanism.

Andean people seen in the clinics appeared to have poor dental care, low standards of personal hygiene, and marginal understanding of the importance of disease prevention. At the same time, they showed a stronger sense of community and willingness to help each other than what is found in most modern societies. They also benefited from a low prevalence of conditions that are prominent in the American society. For example, obesity was estimated to be around $5 \%$ of the patients attending the clinic, a value markedly lower than that reported in the United States: $17 \%$ in children and $35 \%$ in adults [29]. Similarly, cardiovascular diseases were seldom diagnosed. In addition, we noted that hair loss, in either men or women, was a rarity, as was the graying of the hair, even in advanced age.

It is difficult to quantify the benefits a medical mission like this one can have on the indigenous population. The lack of follow-up data and interaction with local physicians prevents us from drawing meaningful conclusions. In the short term, the mission certainly provided relief by delivering medications (such as antibiotics and anti-inflammatory) that are not easily available to this population. Longlasting benefits can perhaps arise if studies like this foster a stronger collaboration with the local health system, promote the implementation of electronic medical records and thus patient follow-up, refine the medication inventory based on the observed disease prevalence, and identify practical objectives for future missions. For example, programs could be implemented to promote better dental hygiene, regular eye exams, and safer sexual practices to reduce the incidence of genitourinary infections. Naturally, century-ingrained dietary and work practices cannot be easily changed. Nevertheless knowing what these practices are should better equip future missions for providing more targeted relief and novel health care solutions.

In summary, the study reports the prevalence of diseases found in rural and mountainous Andean villages of central Peru, providing a foundation for designing basic public health interventions in the same or comparable regions.

Acknowledgments The authors are grateful to Ms. Jennifer Diamond (founder of Hands Across Americas) and Dr. Luis Zuniga (Medical Director of the mission) for the opportunity to participate in the July 2015 Peruvian mission, and to Dr. Cristina Campassi and Ilaria Caturegli for critically reviewing the manuscript.

\section{Compliance with ethical standards}

Conflict of interest None.
Human and animal rights Not applicable to this retrospective study.

Informed consent No informed consent was necessary as the study in fact was considered exempt from institutional review board evaluation on the basis of federal regulation 45 CFR 46.101(b) (research involving the study of existing data recorded in such a manner that subjects cannot be identified).

\section{References}

1. Strachan DP (1989) Hay fever, hygiene, and household size. BMJ 299:1259-1260

2. Bach JF (2002) The effect of infections on susceptibility to autoimmune and allergic diseases. N Engl J Med 347:911-920

3. Clarke CA, Reynolds P, Oakley-Girvan I, Lee E, Lu Y, Yang J et al (2015) Indicators of microbial-rich environments and the development of papillary thyroid cancer in the California Teachers Study. Cancer Epidemiol 39(4):548-553

4. Correale J, Farez MF (2011) The impact of environmental infections (parasites) on MS activity. Mult Scler 17:1162-1169

5. Correale J, Gaitan MI (2015) Multiple sclerosis and environmental factors: the role of vitamin D, parasites, and Epstein-Barr virus infection. Acta Neurol Scand 132:46-55

6. Weinstock JV, Elliott DE (2009) Helminths and the IBD hygiene hypothesis. Inflamm Bowel Dis 15:128-133

7. Bashi T, Shovman O, Fridkin M, Volkov A, Barshack I, Blank M et al (2015) Novel therapeutic compound tuftsin-phosphorylcholine attenuate collagen induced arthritis. Clin Exp Immunol. doi:10.1111/cei.12745

8. Versini M, Jeandel PY, Bashi T, Bizzaro G, Blank M, Shoenfeld Y (2015) Unraveling the hygiene hypothesis of helminthes and autoimmunity: origins, pathophysiology, and clinical applications. BMC Med 13:81

9. Correale J, Farez M (2007) Association between parasite infection and immune responses in multiple sclerosis. Ann Neurol 61:97-108

10. Correale J, Farez M, Razzitte G (2008) Helminth infections associated with multiple sclerosis induce regulatory B cells. Ann Neurol 64:187-199

11. Sanchez O, Judd T (2014) The Neuropsychology of Indigenous ("Indian") Latin Americans: a Beginning. Arch Clin Neuropsychol 29:516

12. de la Cruz MG, Malpartida SB, Santiago HB, Jullian V, Bourdy G (2014) Hot and cold: medicinal plant uses in Quechua speaking communities in the high Andes (Callejon de Huaylas, Ancash, Peru). J Ethnopharmacol 155:1093-1117

13. Toloza SM, Vega-Hinojosa O, Chandran V, Valle Onate R, Espinoza LR (2012) Psoriasis and psoriatic arthritis in Peruvian aborigines: a report from the GRAPPA 2011 annual meeting. J Rheumatol 39:2216-2219

14. Eaton WW, Rose NR, Kalaydjian A, Pedersen MG, Mortensen PB (2007) Epidemiology of autoimmune diseases in Denmark. J Autoimmun 29:1-9

15. Nwankwo T, Yoon SS, Burt V, Gu Q (2013) Hypertension among adults in the United States: national Health and Nutrition Examination Survey, 2011-2012. NCHS Data Brief 133:1-8

16. Vallejo JA, Miranda P, Flores-Felix JD, Sanchez-Juanes F, Ageitos JM, Gonzalez-Buitrago JM et al (2013) Atypical yeasts identified as Saccharomyces cerevisiae by MALDI-TOF MS and gene sequencing are the main responsible of fermentation of chicha, a traditional beverage from Peru. Syst Appl Microbiol 36:560-564 
17. Jha KN (2012) High altitude and the eye. Asia Pac J Ophthalmic $1: 166-169$

18. Adhikari S (2013) Myopia in school children from high mountain region of Nepal. Nepal J Ophthalmol 5:246-249

19. Guo B, Lu P, Chen X, Zhang W, Chen R (2010) Prevalence of dry eye disease in Mongolians at high altitude in China: the Henan eye study. Ophthalmic Epidemiol 17:234-241

20. Wang GQ, Bai ZX, Shi J, Luo S, Chang HF, Sai XY (2013) Prevalence and risk factors for eye diseases, blindness, and low vision in Lhasa, Tibet. Int J Ophthalmol 6:237-241

21. Watts NS, Pajuelo M, Clark T, Loader MC, Verastegui MR, Sterling C et al (2014) Taenia solium infection in Peru: a collaboration between Peace Corps Volunteers and researchers in a community based study. PLoS One 9:e113239

22. Christen U, Bender C, von Herrath MG (2012) Infection as a cause of type 1 diabetes? Curr Opin Rheumatol 24:417-423

23. James JA, Robertson JM (2012) Lupus and Epstein-Barr. Curr Opin Rheumatol 24:383-388
24. Miller SD, Katz-Levy Y, Neville KL, Vanderlugt CL (2001) Virus-induced autoimmunity: epitope spreading to myelin autoepitopes in Theiler's virus infection of the central nervous system. Adv Virus Res 56:199-217

25. Shor DBA, Harel M, Eliakim R, Shoenfeld Y (2013) The hygiene theory harnessing helminths and their ova to treat autoimmunity. Clini Rev Allergy Immunol 45:211-216

26. Shoenfeld Y, Selmi C, Zimlichman E, Gershwin ME (2008) The autoimmunologist: geoepidemiology, a new center of gravity, and prime time for autoimmunity. J Autoimmun 31:325-330

27. Wang L, Wang FS, Gershwin ME (2015) Human autoimmune diseases: a comprehensive update. J Intern Med 278:369-395

28. Thomsen SF (2015) Epidemiology and natural history of atopic diseases. Eur Clin Respir J 2. doi:10.3402/ecrj.v2.24642

29. Ogden CL, Carroll MD, Kit BK, Flegal KM (2014) Prevalence of childhood and adult obesity in the United States, 2011-2012. JAMA 311:806-814 